\title{
The Influence Of Restraint Systems On Panel Behavior
}

\author{
Dawn C. Jegley \\ NASA Langley Research Center, Mail Stop 190, Hampton, VA 23681-2199 \\ E-mail dawn.c.jegley@nasa.gov
}

\begin{abstract}
When a panel is tested in uniaxial compression in a test machine, the boundary conditions are not quite the same as they would be if it were part of a complete structure. A restraint system may be used to simulate conditions found in a complete vehicle. Quantifying the quality of the restraint with only point-measurement devices can leave an inadequate characterization of the out-of-plane behavior. However, today's full-field displacement monitoring techniques allow for much more accurate views of the global panel deformation and strain, and therefore allow for a better understanding of panel behavior. In the current study, the behavior of a hat-stiffened and two rod-stiffened carbon-epoxy panels is considered. Panels were approximately 2 meters tall and 0.76 to $1.06 \mathrm{~m}$ wide. Unloaded edges were supported by knife edges and stiffeners were attached to a support structure at selected locations to restrain out-of-plane motion. A comparison is made between test results based on full-field measurements and analyses based on assumptions of boundary conditions of a completely rigid edge restraint and the absence of any edge restraint. Results indicate that motion at the restrained edges must be considered to obtain accurate test-analysis correlation.
\end{abstract}

\section{INTRODUCTION}

When a panel is tested in uniaxial compression in a test machine, the boundary conditions are not quite the same as they would be if it were part of an entire wing or fuselage structure. The panel is usually supported by a restraint system which may be representative of the support found in an aircraft structure. Quantifying the quality of the restraint with only pointmeasurement devices can leave an inadequate characterization of the out-of-plane behavior. However, today's full-field displacement monitoring techniques allow for much more accurate views of the global and local panel deformation.

The ends of a composite compression panel are usually encased in a potting compound which is surrounded by a steel support to prevent end brooming. The unloaded edges are often supported by metallic knife edges to restrain the panel from deforming in a global single half-wave mode, and to prevent the free edge of a thin skin region from buckling into shorter wavelengths. Analytically, these supports are often approximated by restraining all degrees for freedom except axial shortening for the entire potted region, and restraining all out-of-plane motion along the unloaded edge. In addition, a restraint system is also often included to restrain the panel from out-of-plane motion. A support structure is attached to panel stiffeners, where the connection points are assumed to fully restrain out-of-plane motion but allow in-plane motion. The validity of these assumptions is considered in this paper for three carbon-epoxy panels. One hat-stiffened and two rodstiffened panels loaded in axial compression are discussed herein. In this case, "hat-stiffened" refers to hat-stiffeners in the loading direction and "rod-stiffened" refers to stiffeners with pultruded carbon rods in the stiffeners in the loading direction. Each panel was fabricated by the Boeing Company and provided to NASA Langley Research Center for testing.

\section{TEST ARTICLES AND ARRANGEMENT}

Each panel had stringers in the loading direction and frames perpendicular to the stringers, as shown in figure 1. The hatstiffened panel was $1.885 \mathrm{~m}$ tall and $76.2 \mathrm{~cm}$ wide, and contained three hat-stringers and two blade-frames. The hat-stiffener spacing was $25.4 \mathrm{~cm}$ and the frame spacing was $61 \mathrm{~cm}$. The rod-stiffened panels were $2.032 \mathrm{~m}$ tall and $1.067 \mathrm{~m}$ wide, and contained seven rod-stringers and four hat-frames. The stringer spacing was $15.24 \mathrm{~cm}$ and the frame spacing was $50.8 \mathrm{~cm}$. The hat-stringers and hat-frames were supported by Rohacell foam on the inside of the hats. All three panels were fabricated from dry components that were infused with resin using high temperature and vacuum pressure. Skins, flanges, tear straps and webs were composed of layers of graphite material forms that were prekitted into multi-ply stacks using Hercules, Inc. 
AS4 fibers. Each nine-ply stack had a $\left[45 /-45 / 0_{2} / 90 / 0_{2} /-45 / 45\right]_{\mathrm{T}}$ stacking sequence of approximately $0.132 \mathrm{~cm}$ thickness. Several stacks of the prekitted material were used to build up the desired thickness and configuration. Stringer and frame flanges were stitched to the skin using Vectran fibers; no mechanical fasteners were used for joining. Panels were infused with HexFlow VRM-34 epoxy resin using a VARTM process as described in reference 1.

In the hat-stiffened panel, the skin and hats were composed of two stacks of material with a total approximate thickness of $0.264 \mathrm{~cm}$. The blade-frames were composed of four stacks with a total approximate thickness of $0.528 \mathrm{~cm}$. The hats and blades were 5.5 and $5.0 \mathrm{~cm}$ tall, respectively. Sketches of the hat stiffener and frame cross sections are shown in figures $2 \mathrm{a}$ and $2 \mathrm{~b}$, respectively. For both of the rod-stiffened panels, the sides of the hat frames and the stringer webs were each composed of two stacks with a total approximate thickness of $0.264 \mathrm{~cm}$. The rod-stiffeners contained pultruded rods with a diameter of $0.95 \mathrm{~cm}$ which were surrounded by one stack of material. The rod-stiffeners were $3.78 \mathrm{~cm}$ tall and the frames were $15.2 \mathrm{~cm}$ tall. The skin of one rod-stiffened panel was one stack thick and the skin of the other was two stacks thick. These panels will be referred to herein as the thin-skinned and thick-skinned rod-stiffened panels, respectively. Sketches of the rod-stiffener and hat-frame cross sections are shown in figures $3 \mathrm{a}$ and $3 \mathrm{~b}$, respectively.

Each of the three panels considered in this study had potted loaded ends, metal edge restraints along the unloaded edges, and a steel support structure attached to the frames. The edge restraints and support structure were intended to prevent out-ofplane motion in the form of a single half-wave along the panel length. The edge restraints are shown in figure 1.

The dimensions of the steel tube edge restraints for the three panels are shown in figure 4 . The steel tube was slightly shorter than the length of the panel between the potting to allow for axial shortening during the test. A slot was cut through the wall thickness for the full length of each tube so that the tube could slide over the panel skin. However, since the frames extended to the panel edges, cutouts in the tubes at each frame location were required to accommodate the frames. The edge restraints were required to just touch the surface of the panel. Small fasteners were inserted through holes in the tubes so the fasteners could be used to close the slot to match the skin thickness after the tube was in position. Teflon tape was placed between the panel surface and the restraint so that the panel would not bind up on the restraint during shortening. The edge restraints for the thick-skinned rod-stiffened panel was the same as for the hat-stiffened panel except for the different spacing for the cutouts for the frames, as indicated in the figure. The tubes for the thin-skinned rod-stiffened panel had a larger diameter and wall thickness than for the other two panels.

Additionally, since the frames would not be totally free to move in a real structure, a support structure was used on all panels to prevent out-of-plane motion at two locations on each frame, as shown in figure 5. Steel channel arms were attached to clips on the frames and the arms were attached to uprights behind the panel. The uprights were attached to a steel I-beam sitting on the floor. These arms were pinned to the clips and to the uprights so the restraints did not restrict rotation of the frames during loading, as shown in the close-up in figure $5 \mathrm{~d}$. However, the frame support structure was not attached to the floor or test machine during loading for the hat-stiffened or thick-skinned rod-stiffened panel. The floor I-beam was attached to the floor and angle bars were attached between the frame support and the floor during the test of the thin-skinned rodstiffened panel as shown in figure 5c. In addition, lateral supports connecting the midlength position of the edge supports to the frame support assembly were added for the thin-skinned panel test to ensure that the tubes could not move out-of-plane during loading. These features are noted in figure $5 \mathrm{c}$. Shims were also added to take up tolerances where the arms were pinned to the uprights in the frame restraint system.

\section{INSTRUMENTATION AND TEST PROCEDURE}

Each panel was monitored during loading using approximately 80 strain gages, 8 LVDTs and a full-field optical measurement system. The optical measurement or Vision Image Correlation (VIC) system [2] was used to obtain full field displacement and strain results for the unstiffened side of the panel skin during the loading of each specimen. The VIC system required a black and white speckle pattern be painted on the specimen surface, and used two cameras positioned at different angles to the specimen surface to simultaneously photograph the specimen at set intervals during the test. In these tests, the specimen was photographed every 2 to 5 seconds, resulting in approximately 150 time steps of data. The VIC system also recorded the load from the test machine so images could be related to the corresponding load. The VIC system compared the photographic images and produces three-dimensional displacements and strains. For each panel, the section between the centermost frames was monitored using the VIC system. A typical VIC arrangement is shown in figure 6.

Photographs of the hat-stiffened, thick-skinned and thin-skinned rod-stiffened panels in the test machine are shown in figures $5 \mathrm{a}, 5 \mathrm{~b}$ and $5 \mathrm{c}$, respectively. The stiffened surface was painted white to improve the video images and was not monitored using VIC since restraints, instrumentation and shadows would limit the clear vision area of a VIC image. 
Each panel was loaded in a series of tests at a load rate of between 100 and $200 \mathrm{kN} / \mathrm{min}$. Even though each panel was subjected to barely-visible impact damage prior to loading, these impacts did not significantly affect the panel behavior and are not visible in the VIC data, so this damage is not considered in the current paper.

\section{FINITE ELEMENT ANALYSIS}

An analytical evaluation of each panel was conducted using the computer code STAGS [3]. The finite element model for the hat-stiffened panel is shown in figure 7. The others used a similar mesh with similar numbers of elements. The hat-stiffened panel model included 13,656 quadrilateral shell elements representing the skin, flanges, hats, and frames. The foam inside the hats in all three panels was modeled as part of the shell elements representing the hat tops and webs. This assumption was adequate since the foam carried a negligible amount of load but restrained buckling of the hat webs. For all three panels, the material properties are based on the compression properties for a stack of material [1], such that the stack axial stiffness is 63.6 GPa, the lateral stiffness is $32.1 \mathrm{GPa}$, the shear stiffness is $15.6 \mathrm{GPa}$, and Poisson's ratio is 0.397 . In addition, the pultruded rods were modeled as beam elements with axial stiffness $124 \mathrm{GPa}$ for both rod-stiffened panels.

The loaded ends of each panel inside the potting were restrained by forcing all lateral and out-of-plane displacements to be zero inside the potted region. Frame supports were not included as restraints in the analyses since test data indicates that the frames moved out-of-plane during loading. Two types of edge restraint assumptions were used for each panel. First, the unloaded edges were restrained such that no out-of-plane motion was permitted but all other degrees of freedom were allowed. Second, no edge restraint was included, allowing the unloaded edge to deform in any direction.

\section{RESULTS AND DISCUSSION}

The experimental full-field deformation in the center region between frames for the hat-stiffened panel is shown in figure 8 for a load level of approximately $640 \mathrm{kN}$, which is immediately prior to the failure load of $641.7 \mathrm{kN}$. The edges of the panel display an out-of-plane deformation of approximately $0.9 \mathrm{~cm}$ despite the presence of the edge restraints. Lines of data for out-of-plane motion near the left edge, and midbay between hats were extracted from the VIC data and plotted in figure 9 as a function of vertical position. Frame locations are indicated by the light black dashed lines. Out-of-plane deformations along the left edge and midbay between hats from test and the two analyses of the hat-stiffened panel are shown in figure 9a for the full panel length, and in figure $9 \mathrm{~b}$ for the center section between frames, for a load of approximately $640 \mathrm{kN}$. The analytical results show the full panel length and are represented by solid lines, while test results were only obtained between two center frames and are shown as dashed lines. Panel edge deformations are shown in green lines, and left and right midbay deformations are shown in red and blue lines, respectively. Since the panel is symmetric, the analysis indicates that the two midbay deformations are the same, so only blue and green lines for analysis are seen in the plot.

Significant deformation is seen for all three locations in the test results. Even at the restrained edges and frame locations, the panel is not fully restrained for this load level. At this load level the relatively uniform edge and frame deformations indicate that the edges and frames have moved out-of-plane by approximately $0.76 \mathrm{~cm}$ at the frame locations despite the presence of the restraints. A comparison of the edge deformation and the midbay deformation, with the knowledge that the loaded ends of the panel could not move out-of-plane, imply that the panel is taking on a single half-wave mode shape along the panel length with an amplitude of approximately $0.9 \mathrm{~cm}$ while the midbay measurements indicate that a local deformation with an amplitude of approximately $0.5 \mathrm{~cm}$ is superposed on this global mode.

The predicted out-of-plane motion of the unstiffened side of the hat-stiffened panel resulting from the assumptions of the restrained and unrestrained unloaded edges are shown in figure 10 for a load of approximately $640 \mathrm{kN}$. These boundary conditions result in the same local buckling pattern, but the global behavior differs. The midbay deformation between the stiffeners shows the same pattern as the test data, but the amplitudes are different. When no restraint is included on the unloaded edge, the 0.264 -cm thick skin buckles along the free edge but edge buckles are not seen in the test data. The hatstiffened panel supported its Design Ultimate Load of $600.5 \mathrm{kN}$ by carrying load after the skin buckled locally, so the unanticipated edge deformations along the frames and edges had no major impact on the test results.

A similar process of evaluation was completed for the rod-stiffened panels. The only difference between the two rodstiffened panels is the thickness of the skin. The experimental full-field out-of-plane deformations are shown in figure 11 for a load of approximately $915 \mathrm{kN}$ for the thick-skinned panel and $885 \mathrm{kN}$ for the thin-skinned panel, which are slightly less than the failure loads of 918.6 and $889.6 \mathrm{kN}$, respectively. 
Out-of-plane deformations at a load level just prior to failure along the left edge, midbay location nearest the center of the panel, and midbay location one bay away from the center are shown in figure 12 for the thick-skinned panel and figure 13 for the thin-skinned panel. The analytical results show the full panel length and are represented by solid lines, while test results were only obtained between two center frames and are shown as dashed lines. The edge is shown in green and the midbay locations are shown in red and blue. Frame locations are indicated by light black dashed lines. These results show that the edges and frame locations again deform out-of-plane. Test results show that in the thick-skinned panel, one edge of the panel moved out-of-plane by approximately $1.2 \mathrm{~cm}$, shown in figure 12b, while the thin-skinned panel moved out-of-plane approximately $0.20 \mathrm{~cm}$, shown in figure $13 \mathrm{~b}$. The thick-skinned panel failed at a load of $918.6 \mathrm{kN}$ while the thin-skinned panel failed at a load of $889.6 \mathrm{kN}$. The modifications to the support structure reduced the out-of-plane motion for approximately the same load level and allowed the thin-skinned panel to support almost as much load as the thick-skinned panel. Both panels display local buckling between the stiffeners. Notice that the edge in both unrestrained edge cases shows a global single half-wave deformation shape along the panel length, while the midbay locations show local deformations between the frames superposed on the global shape. Buckling mode shapes of several half-waves occur between the stiffeners and add to the global deformation. In the thick-skinned panel, the test data indicates a larger amplitude of the global buckle than either of the analysis cases, and local buckle amplitudes which are approximately the same as seen in the unrestrained edge case. In the thin-skinned panel the test results show little global deformation and local buckle amplitudes which are close to what is predicted for the unrestrained edge case.

The out-of-plane motion of the unstiffened side of the rod-stiffened panels resulting from the assumptions of the restrained and unrestrained unloaded edges are shown in figures 14 and 15. Analytical result for the thick-skinned rod-stiffened panel for the restrained and unrestrained conditions at a load of $890 \mathrm{kN}$ are shown in figure 14a and 14b, respectively. Analytical result for thin-skinned panel with restrained edges at a load of $934 \mathrm{kN}$ is shown in figure $15 \mathrm{a}$. Analytical result for thinskinned panel with unrestrained edges at a load of $778 \mathrm{kN}$ is shown in figure $15 \mathrm{~b}$. The deformation patterns are similar but not identical to the test data shown in figure 11. The thick-skinned and thin-skinned rod-stiffened panels support 70 and 97 percent of their Design Ultimate Loads, respectively. The lack of adequate edge restraints appears to have contributed to the premature failure.

For all three panels, the VIC system was critical to understanding the effect of the restraint system. Test results indicated that the restraint system for the hat-stiffened panel did not fully constrain the panel as intended. However, the panel design limited the global buckling and allowed local buckling to occur. The global buckling was not significant enough to prevent the panel from meeting its design requirements. The restraint system for the thick-skinned rod-stiffened panel did not fully constrain the panel as intended, which led to global buckling and premature failure. The modified restraint system for the thin-skinned allowed small deformations at the restraint points, however the panel displayed the expected local buckling and supported 97 percent of its design load.

\section{CONCLUDING REMARKS}

Three composite panels were loaded to buckling and failure in axial compression. In each case, the panel deformation was a combination of a global one-half wave deformation shape and a local multi-wave shape between stiffeners. The amplitude of the global wave was dependent upon the edge restraint system. Both test and analyses indicate that the restraint system did not fully restrain the edges of the panels during testing. Without the measurements at the panel edges provided by the full field measurement system, the edge behavior would not have been quantified. An improved restraint system was used for the thin-skinned rod-stiffened panel because, by the time of that test, it was understood that the prior restraint systems were not limiting out-of-plane motion as well as had been assumed. This understanding of the limitations of the restraint system relied upon the data provided by the full-field measurement system.

\section{REFERENCES}

[1] Velicki, Alex, "Damage Arresting Composites for Shaped Vehicles, Phase I Final Report, NASA CR-2009-215932, September 2009.

[2] McGowan, David M., Ambur, Damodar R., and McNeil, Stephen R. 2003. "Full-field Structural Response of Composite Structures: Analysis and Experiment," presented at the $44^{\text {th }}$ AIAA/ASME/ASCE/AHS Structures, Dynamics and Materials Conference, AIAA 2003-1623, Norfolk, VA, April 2003.

[3] Rankin, C. C., Brogan, F. A, Loden, W. A., and Cabiness, H. D. 2001. "STAGS User Manual, Version 4.0." Lockheed Martin Missiles and Space Company, Incorporated. 
FIGURES

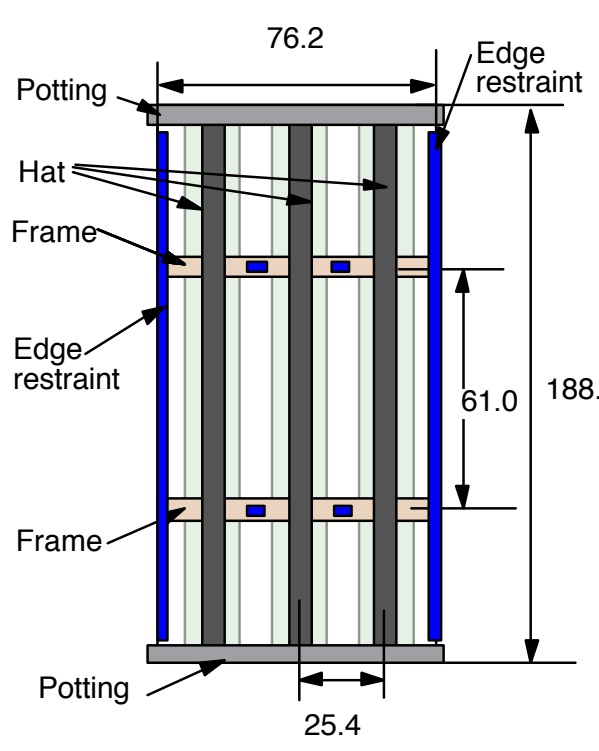

- Frame support locations

a Hat-stiffened panel.

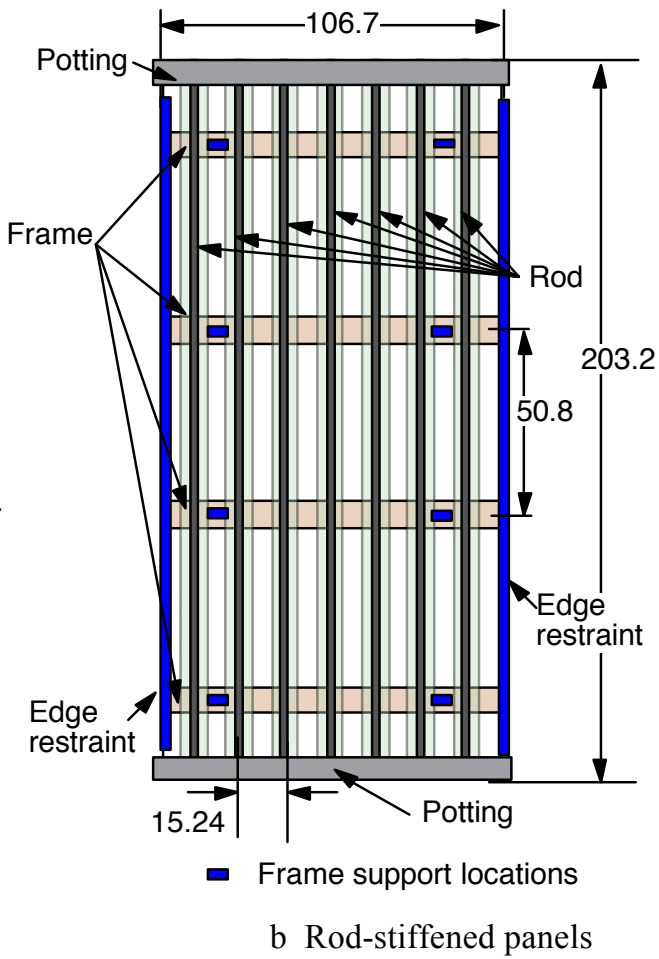

b Rod-stiffened panels

Fig 1 Panel geometry. Dimensions are in $\mathrm{cm}$.

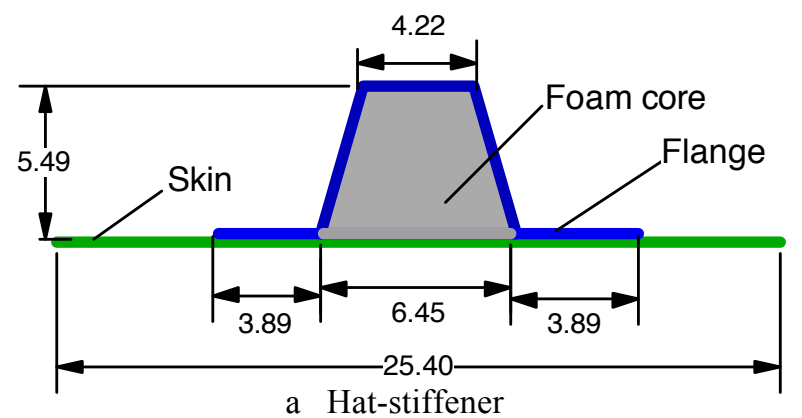

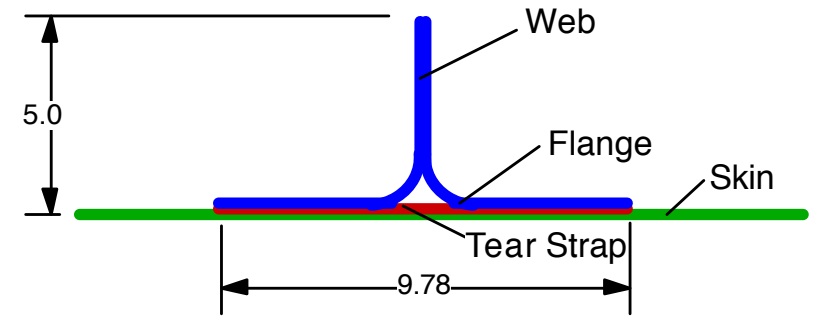

b Blade-frame

Fig 2 Stiffeners in hat-stiffened panel. Dimensions are in $\mathrm{cm}$.

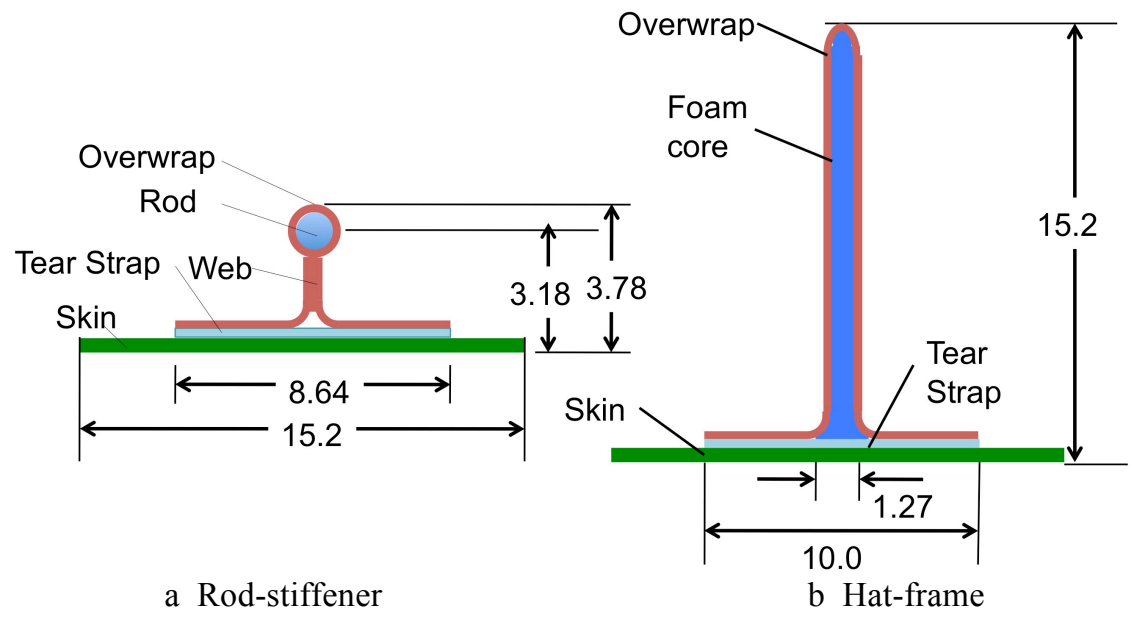

Fig 3 Stiffeners in rod-stiffened panels. Dimensions are in $\mathrm{cm}$. 


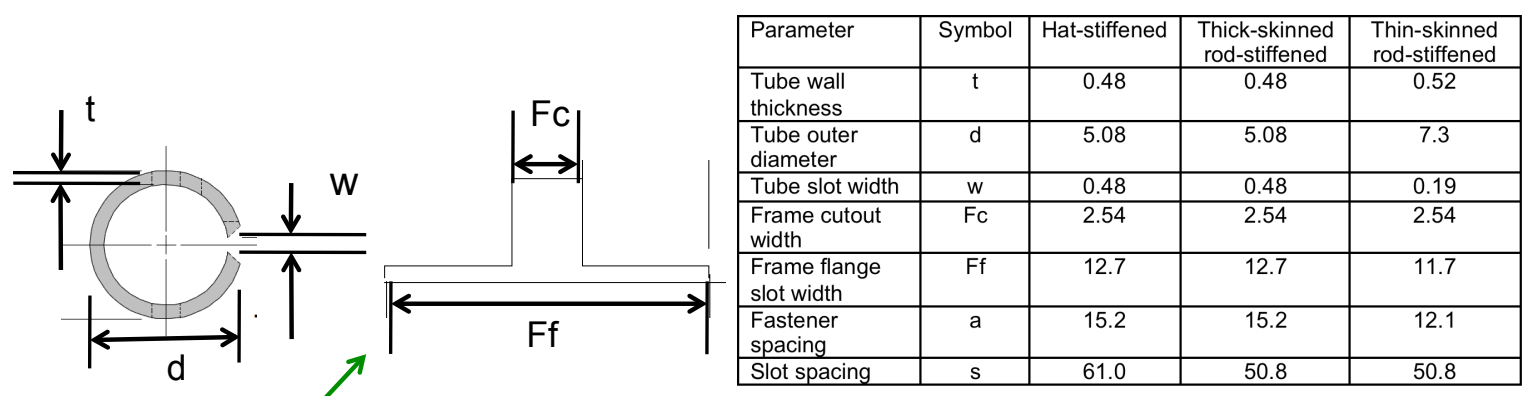

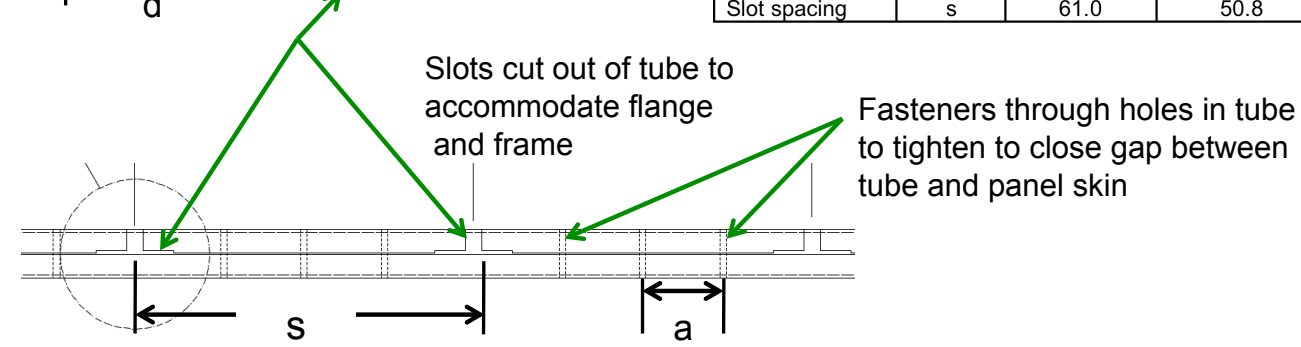

Fig 4 Edge restraints with dimensions in $\mathrm{cm}$.

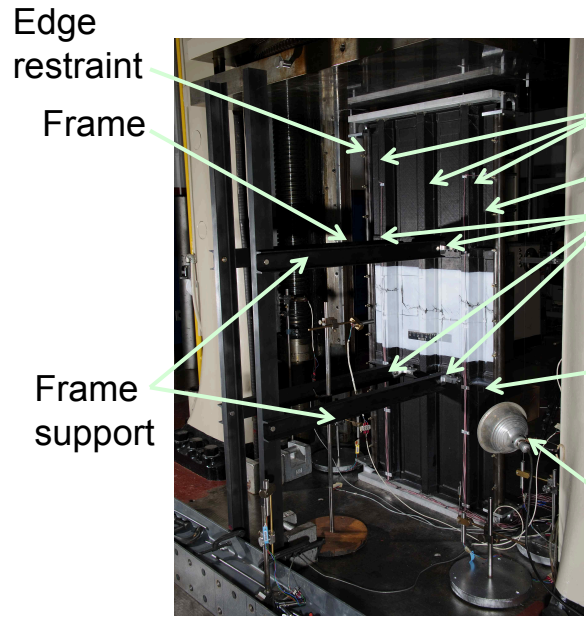

a Hat-stiffened panel

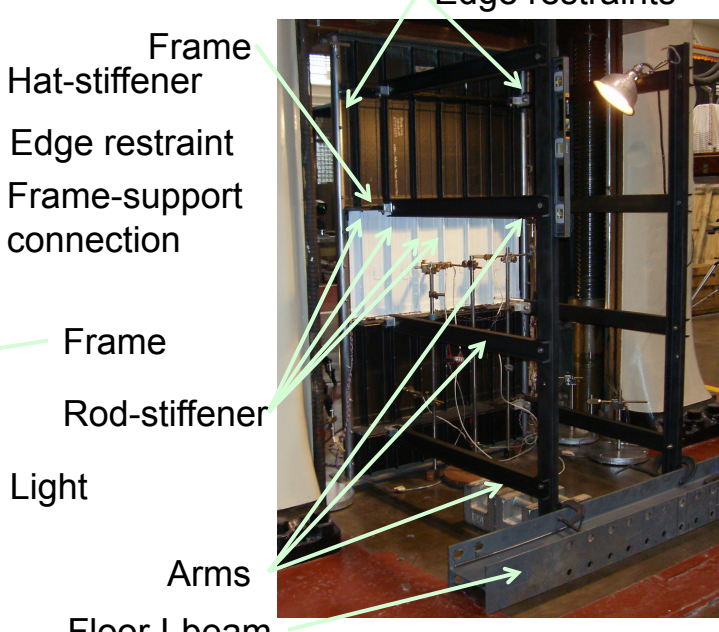

Floor I-beam

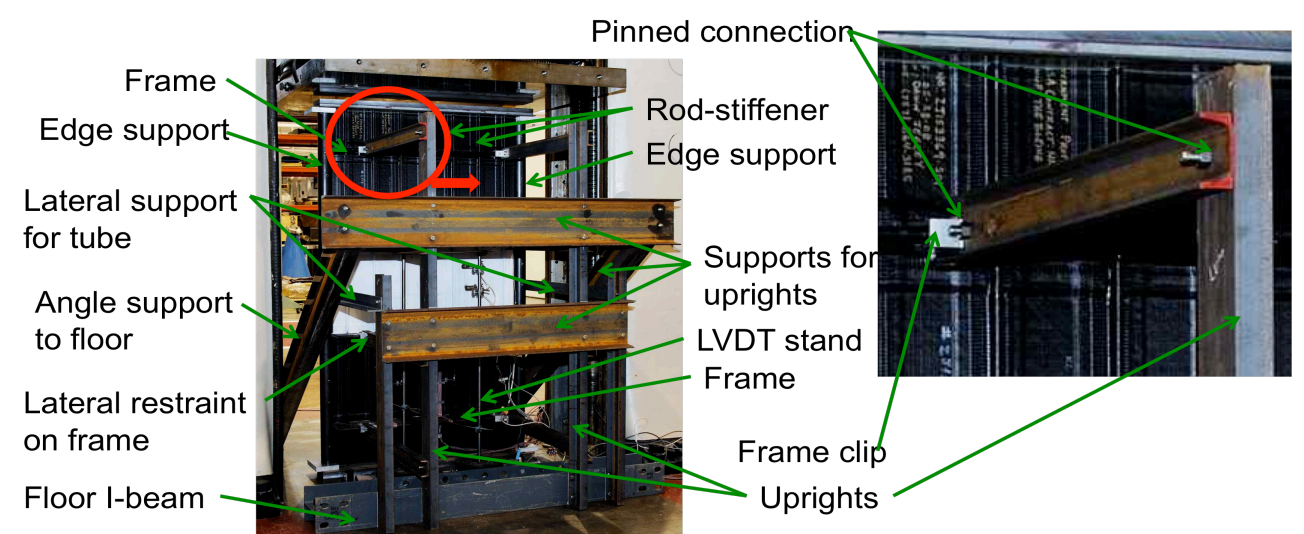

c Thin-skinned rod-stiffened panel

d Close up of frame support arm connections

Fig 5 Panels in test machine. 


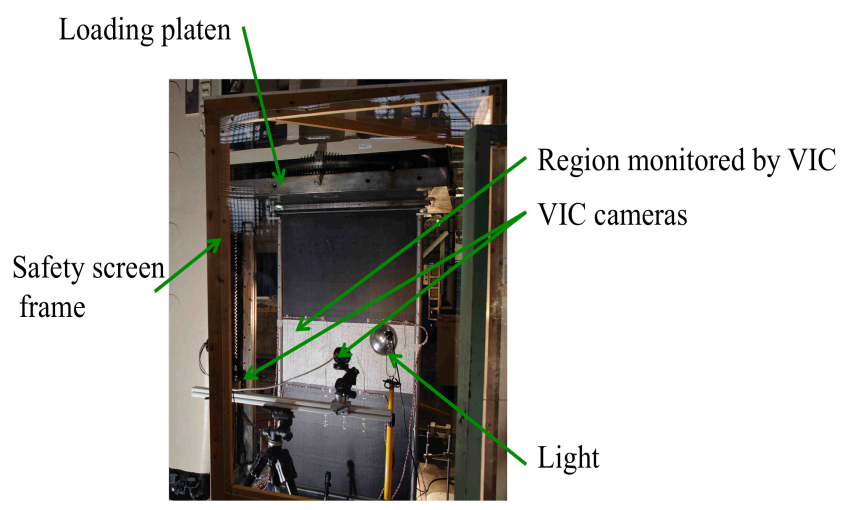

Fig 6 Vision Image Correlation System.

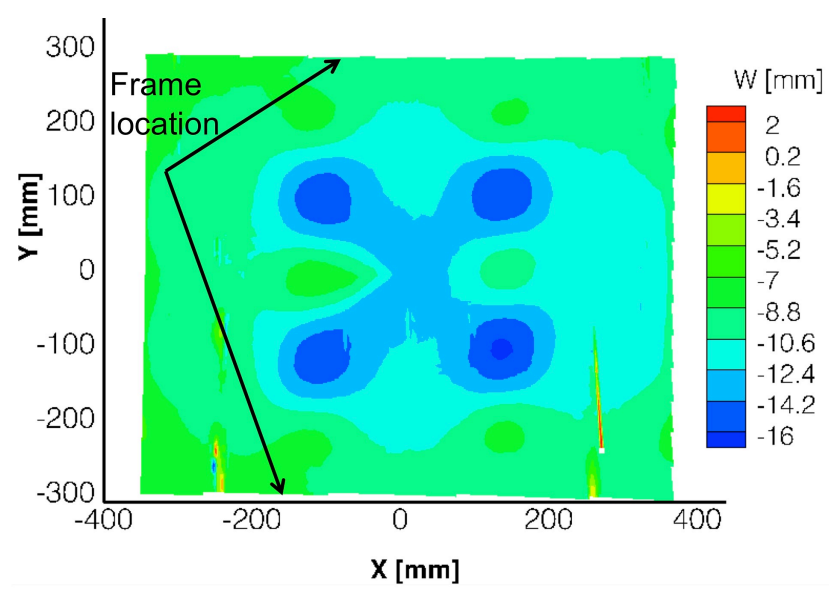

Fig 8 Experimental full-field out-of-plane deformation in center region of hat-stiffened panel at $99.8 \%$ of failure load.

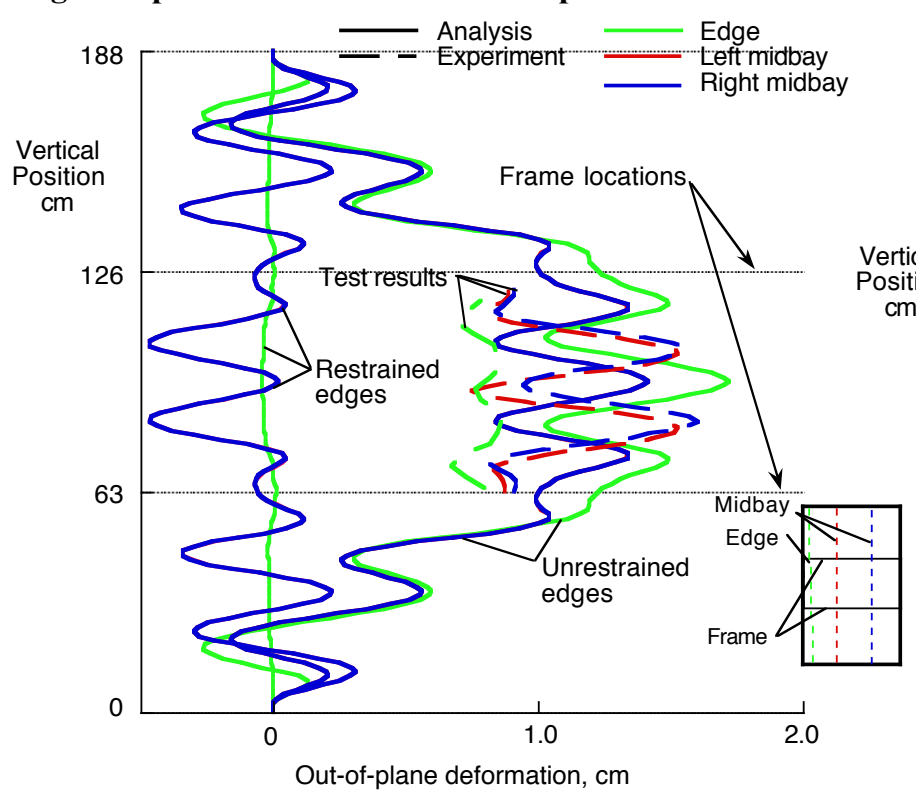

a Full panel length
13,981 nodes

14,193 elements

83,886 DOF

Fig 7 Finite element model of the hat-stiffened panel.

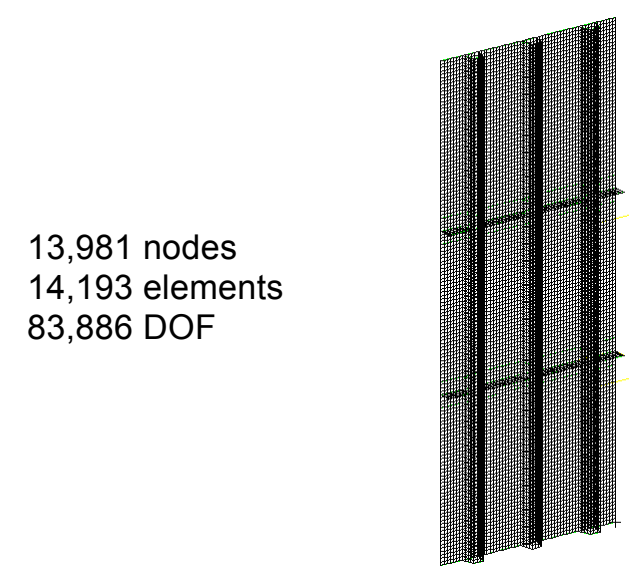




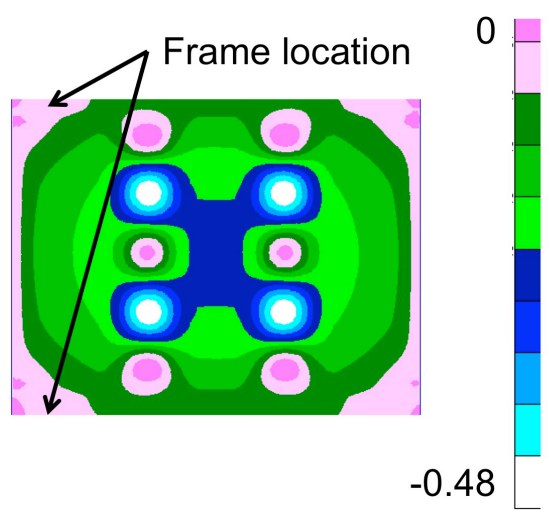

a Restrained unloaded edges

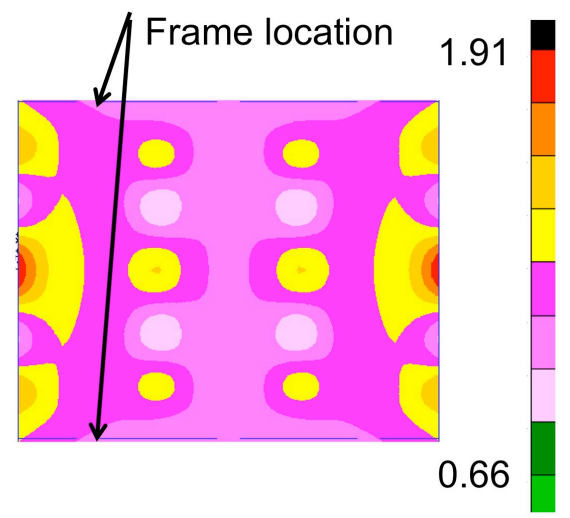

b Unrestrained unloaded edges

Fig 10 Predicted out-of-plane deformation of the unstiffened surface of the hat-stiffened panel at a load level near failure.

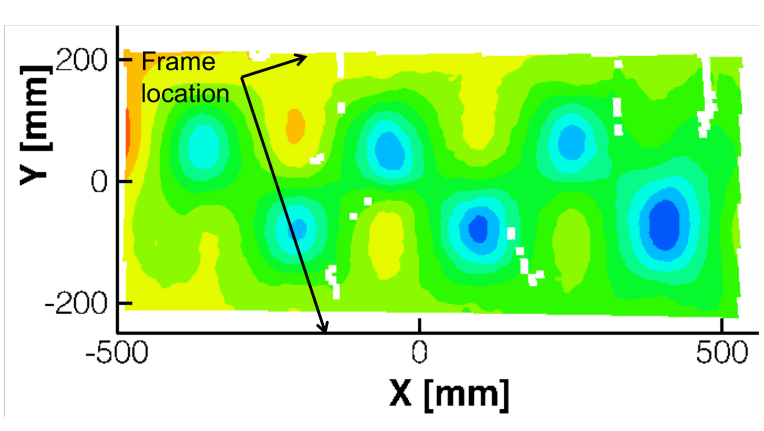

a Thick-skinned panel

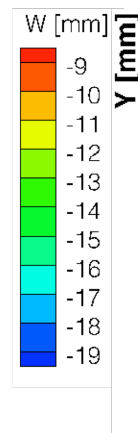

$-200$

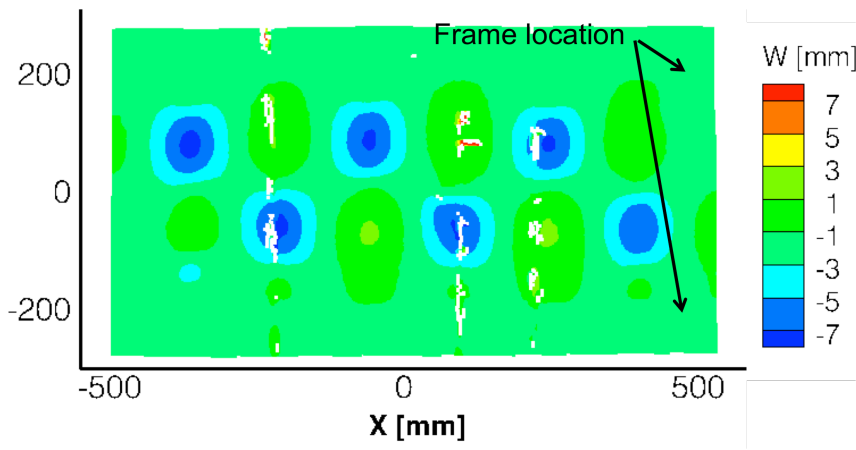

b Thin-skinned panel

Fig 11 Experimental full-field out-of-plane deformation in center region of rod-stiffened panels at approximately $99 \%$ of failure load.

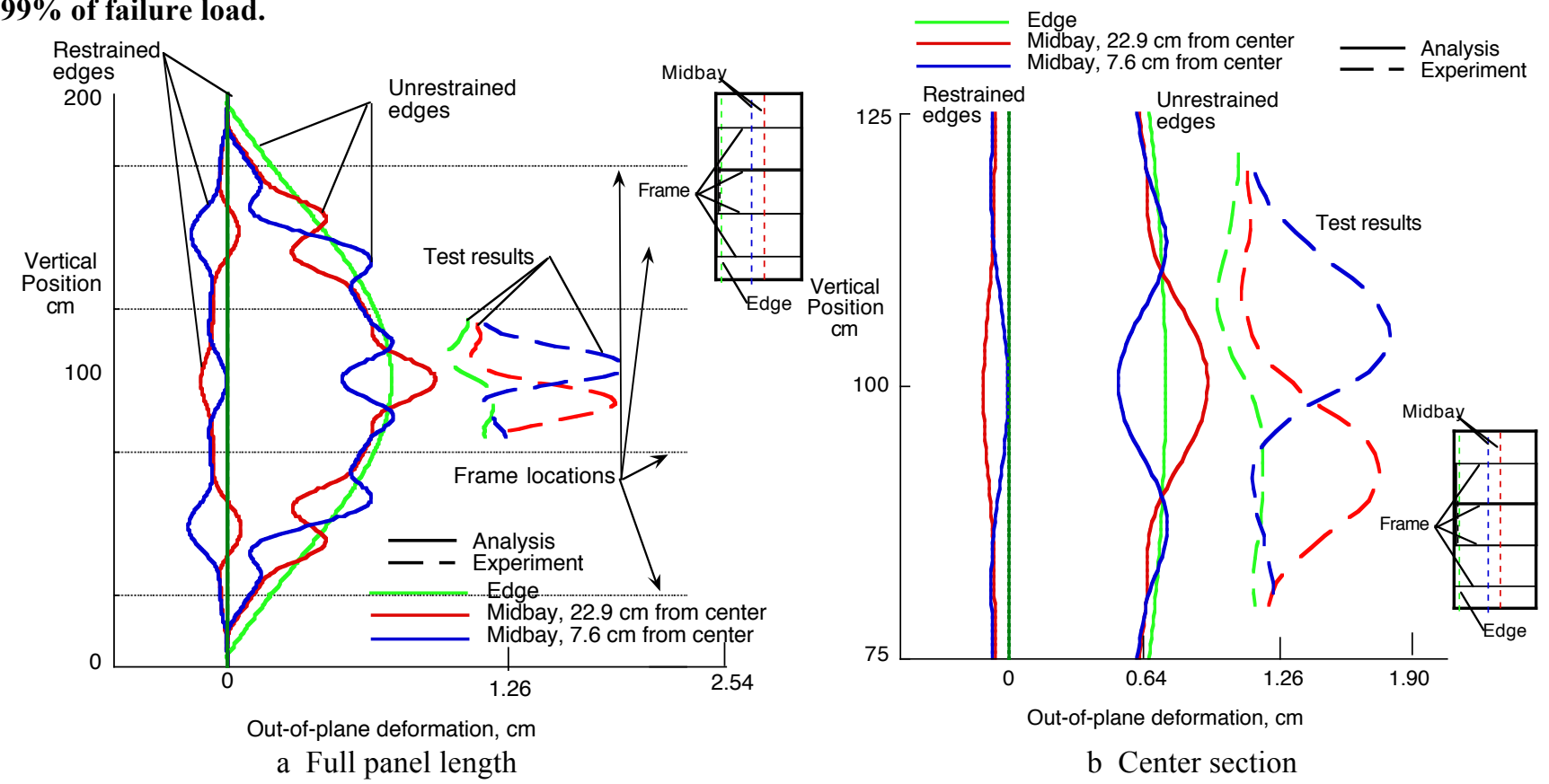

Fig 12 Out-of-plane deformation of thick-skinned rod-stiffened panel at a load of approximately the failure load. 


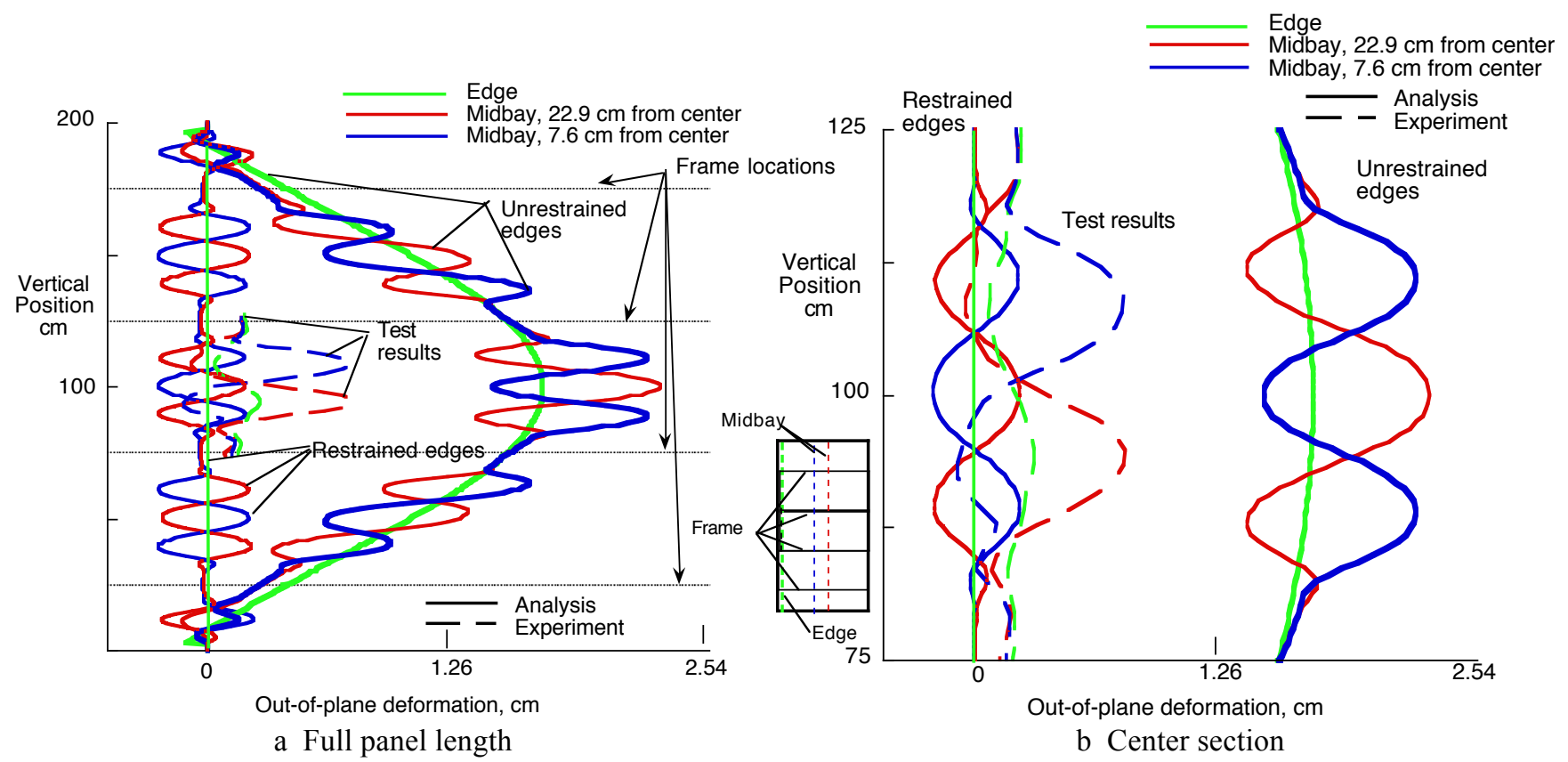

Fig 13 Out-of-plane deformation of thin-skinned rod-stiffened panel at a load of approximately the failure load.

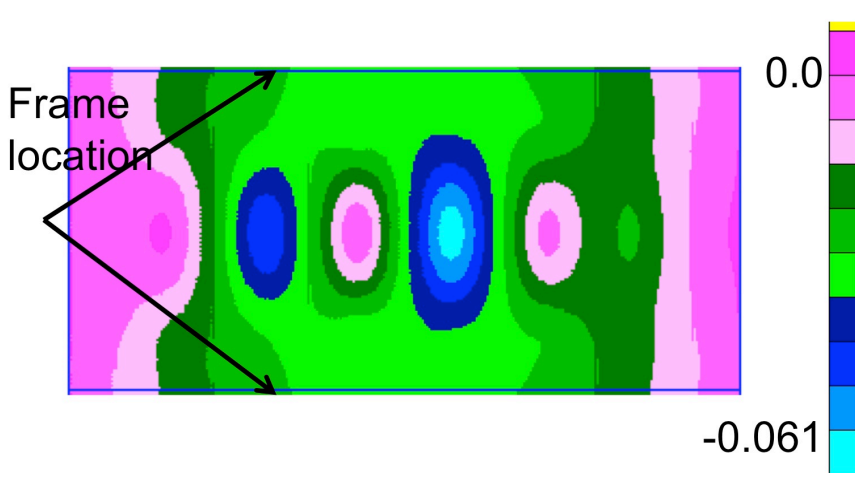

a Restrained unloaded edges
Frame
location

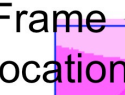

b Unrestrained unloaded edges

Fig 14 Analytical predictions of out-of-plane deformation the thick-skinned rod-stiffened panels at a load of approximately failure load.

$$
0.14
$$

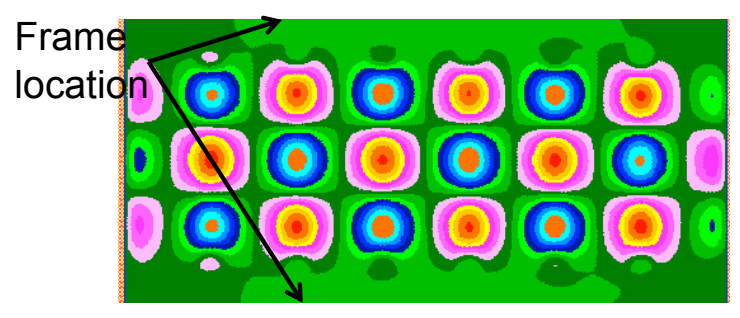

$-0.14$

a Restrained unloaded edges

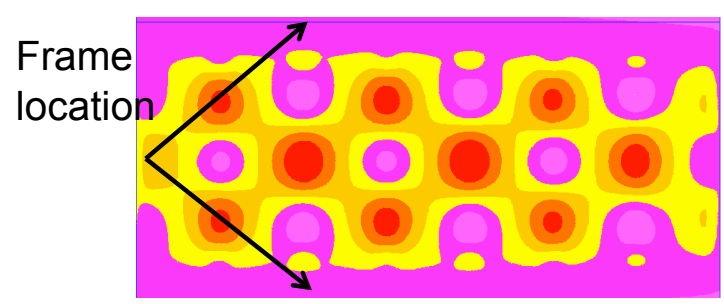

0.91

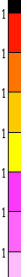

0.46

b Unrestrained unloaded edges

Fig 15 Analytical predictions of out-of-plane deformation the thin-skinned rod-stiffened panels at a load of approximately failure load. 